Roberto Verzola:

\title{
21st-Century Political Economies: Beyond Information Abundance
}

\begin{abstract}
As a result of the relatively low cost of digital reproduction, a global transformation is occurring in the nature of products and processes and in types of goods and services. Arising from information abundance, this global transformation is making the phenomenon of abundance a major field of study, not only for economists but also for other social scientists and physical scientists as well. This essay proposes an economic definition of abundance and a typology of sources of abundance. It argues that real economic abundance can come about only when the demand for a good is finite and the plentiful supply makes the abundant good affordable enough to all members of society. It lists an abundance-nurturing ethic as a major goal of abundance management, and encourages economists to make abundance together with scarcity their conceptual point of departure. Finally it links the phenomenon of abundance to the concept of the commons.
\end{abstract}

\section{Agenda}

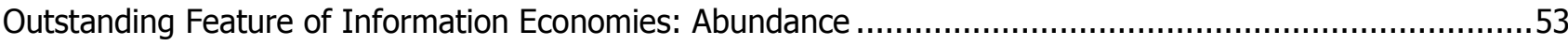

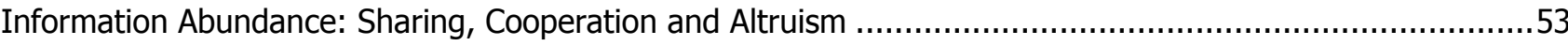

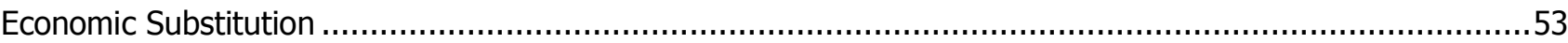

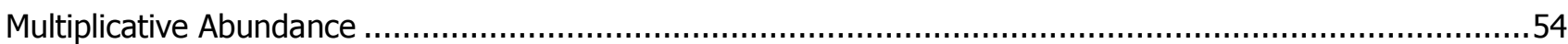

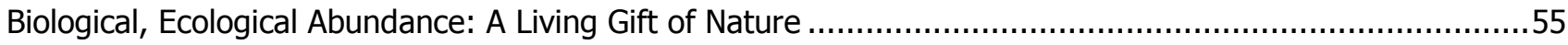

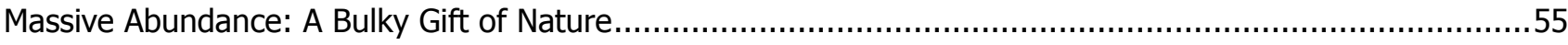

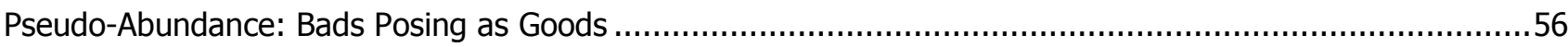

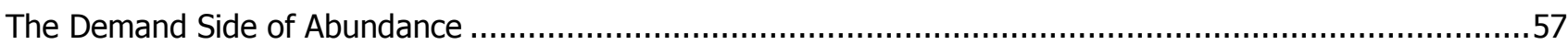

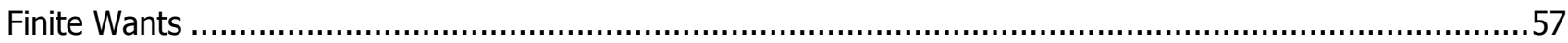

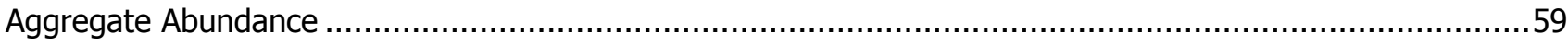

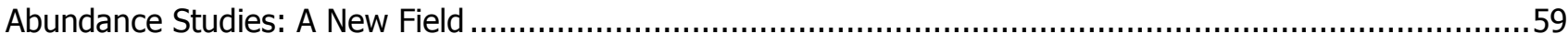

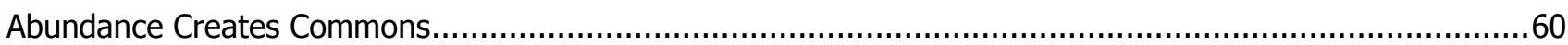

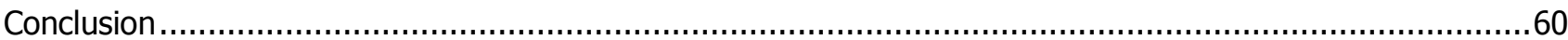

\section{Author}

Roberto Verzola

- Roberto Verzola is an engineer who is also a social activist. His current involvements include the Philippine Greens, Halalang Marangal (Network of Citizens for Honest Elections and Truthful Statistics), SRI-Pilipinas, and the Bulletin Board. He is also a part-time consultant with the Philippine Rural Reconstruction Movement (PRRM).

- $\bowtie$ rverzola@gn.apc.org $\square$ http://rverzola.wordpress.com

Relevant Publications:

- "Undermining Abundance." In Gaelle Kirkorian and Amy Kapcinsky (Eds.). From Intellectual Property Rights to Global Knowledge Sharing. New York: Zone Books. (in press).

- "Studying Abundance”. 2008.

- Toward a Political Economy of Information: Studies on the Information Economy. Quezon City: Constantino Foundation, 2004. 
The key technologies that mark best the transition from the twentieth to the twenty-first century are the new information and communications technologies (ICTs). These new ICTs are at the core of the global information infrastructure and emerging information economies. These ICTs, the Internet and information economies have spawned services such as electronic mail and mailing lists; online sites for sharing text, audio, photos, video, databases, software, DNA sequences, and whatever else could be turned into bits, bytes and files; search engines for locating specific tools, services and content; and portals that collect, organize, improve and recombine existing material as well as attract new material. They are transforming business, education, mass media, culture and other information-intensive sectors of society. Their impacts are also spilling over to housing, transportation, agriculture, and other human activities not usually associated with high information content.

Because of their distinctive features, these ICTs, the Internet and the emerging information economies are bound to shape in significant ways the political economy of the 21st century. and modes of production, another in the world of biological processes, their complexity and organicity.

\section{Outstanding Feature of Information Economies: Abundance}

To those who are part of it, the most outstanding feature of the $21^{\text {st }}$ century economies emerging out of the new ICTs is the abundance of both old and new information content, tools and services - some of which were not necessarily generated by computers but, having been digitally converted from their original format, are now available online. ${ }^{1}$

This outstanding feature can be attributed mainly to a new-found ability made possible by the new ICTs - the unlimited reproduction of exact copies of originals over any number of generations, for distribution over electronic networks or more traditional outlets through various transportable physical media.

This ability, in turn, has turned information goods into a unique commodity, whose cost of producing an extra unit is approaching zero. This diminishing marginal cost can be seen clearly whenever one makes a copy of a digital file, either by downloading it from a network to one's hard disk or by saving a copy to a compact disc or a DVD. The social, economic and technological consequences of the nearzero marginal cost of reproducing information goods gives the information economy its distinctive features.

\section{Information Abundance: Sharing, Cooperation and Altruism}

The near-zero marginal cost of copying information goods makes them nonrival goods, i.e., one can enjoy the good without diminishing other people's enjoyment of the same goods, just as taking a photograph of a beautiful scenery does not prevent others from taking their own photographs. It is a perfect situation for sharing, because one can copy and share the good without losing it, resurrecting what has been variouly called the gift economy or the economy of altruism.

Consider a situation where one has a piece of information, and another has a second piece. Sharing enables both to have the two pieces. Together, the two pieces may, in turn, lead to a third piece, deduced from the first two. The third and the original two, pieced together, may further lead to a new deduction. This synergism, where the result is more than the sum of its parts, can result in explosive information growth. A piece of bread must be divided to be shared; in contrast, knowledge shared multiplies. This near-magical property of information has been compared to the Biblical miracle of the loaves.

\section{Economic Substitution}

Economics is, among other things, cost-driven. In general, producers tend to shift from higher cost materials and processes to lower cost substitutes that make their operation more profitable, and consumers from higher priced goods and services to lower priced substitutes that enable them to buy more goods. Economists call this the "substitution rule". $^{2}$

2 Samuelson and Nordhaus p. 127.

1 Anderson. 
As the prices of information goods go down, they will tend to be substituted for other types of goods. This can be seen in the increasing variety and volume of information commodities, such as software, e-books, e-games, databases, online journals, online music, online video, and other ICT goods, services and activities. This can also be seen in the increasing information content of material goods as costly manual, electro-mechanical, or chemical processes and parts are implemented in low marginal cost software running in mass-produced microprocessors.

This substitution of the electronic for the electromechanical, digital for the analog, software for hardware, information-intensive "intelligent" methods for energy-intensive "brute force" methods, and information goods for physical goods will, according to economic theory, continue until a new maximum is reached in terms of profits for every producer and utility for every consumer. This will also draw additional investments into more profitable ICT businesses, further altering the mix between agriculture, industry and the information sector within economies. We are witnessing today a global process of substitution in products and processes and in types of goods and services. This process began in the 1980 s and the 1990s with the widespread use of digital electronics, microprocessors and electronic networks. The end of this momentous global substitution process is not yet in sight, especially since the marginal costs of information goods continue to diminish, and the cascades of old and new abundance triggered by this process have not fully run their course.

Thus pressure continues to build upon every provider of goods and services in every sector of the economy to turn to ICTs, with new technologies and businesses emerging to facilitate and speed up this process. To give a few examples:

- The knowledge, publishing, media and entertainment industries are now all converging on the Internet.

- Whenever possible, the movement of people and material goods is being replaced by the movement of ideas and information goods, over the Internet.

- The face of health, education, and other personal services is changing through automation and networked operations, also over the Internet.

- With the pace of gene sequencing speeding up and with genetic engineering on the verge of breakthroughs in converting stored digital information about DNA sequences back to live DNA, the whole biological sector may soon become part of the same convergence, unless safety considerations intervene.

- Manufacturing will be revolutionized by software-driven desktop fabricators, which can do 3-D printing using various media, including electronic media. $^{3}$

- When Moore's Law eventually takes hold over thin-film photovoltaic cells and their prices reach a tipping point, the public will finally be enabled to start tapping for electricity generation the greatest abundance of all - the sun's energy. 4

- Financial transactions are initiated, negotiated and consumated on the same information infrastructure and are often executed by computers programmed to respond automatically to changes in prices and trends.

- Technologically lagging countries are becoming hosts to encoding facilities, call centers and other left-over industries that serve mostly customers in technologically leading countries.

\section{Multiplicative Abundance}

We will call the archetype of abundance that is created when the cost of reproducing the resource approaches zero, multiplicative abundance. Goods belonging to this archetype are abundant because the means for making multiple identical copies have become so accessible and the cost of doing so has become so low, that they are easily reproduced essentially for free. This dynamic is fast becoming the driving force of $21^{\text {st }}$ century economies.

To even acknowledge at all the existence of abundance is a huge conceptual leap for many economists, whose fundamental assumptions are based on scarcity. Some economists even say that abundant goods cease to be interesting because the problem of scarcity has been solved. But if abundance solves the problem of scarcity, shouldn't economists devote as much time to the solution as to the problem itself? The answer should be obvious. Indeed, the study of abundance should be a major field of study, not only for economists but

\footnotetext{
3 Gershenfeld p.72-75.

4 See, for instance, Hunt, Rich.
} 
also for other social scientists and for physical scientists as well.

Having identified one archetype of abundance, which we called multiplicative abundance, we should at once be curious if there are other archetypes. It turns out that there are a few more archetypes of abundance. One archetype is brought about by selfreproduction.

\section{Biological, Ecological Abundance: A Living Gift of Nature}

While the abundance of ideas and knowledge in the information sector comes from the intrinsic human urge to communicate and to share, in agriculture and nature it comes from the intrinsic ability instinctive urge, in fact - of living organisms to reproduce themselves. All living organisms reproduce their own kind and are therefore a source of biological abundance. Their biological design enables most of these organisms to tap solar energy directly through photosynthesis, or indirectly by feeding on organisms that have stored this energy in their bodies. As living organisms increase their numbers, they also organize themselves into a food web of producers and consumers - vegetarians, omnivores, carnivores, predators, decomposers, and various other ecological players, creating a selfmaintaining ecological system that from a human perspective can last essentially indefinitely. A society that learns how to tap these ecological systems as natural capital can generate with minimal effort unending flows of natural income for meeting the needs of that society's members. This abundance archetype may be called the reproductive archetype.

Reproductive abundance is essentially a gift of nature for Homo sapiens. We simply need to learn how this abundance has come about, to preserve and enhance the biological and ecological processes that lead to this abundance, and to protect these processes from threats that can lead to disruption or failure.

Left to their own, forests, grasslands, soils of all kinds, ponds, rivers, lakes, bays, seas, oceans, and waters of all kinds will teem with life, almost every ecological niche occupied by one or more species. By their very nature, as long as the right conditions exist for the reproductive processes to occur, ecological systems of interacting biological webs of organisms will provide us a timeless source of abundance.
Properly tapped, this abundance of life can further lead to cascades of abundance, promising a cornucopia of agricultural, biological, natural and ecological goods and services for human societies.

The basic management approach to this archetype is to recognize the many natural incomes possible from one source, to withdraw these as needed while ensuring that the natural capital is preserved and enhanced, so that the resource can provide human societies perpetual income streams. This requires intimate knowledge and deep understanding of biological, ecological and other natural processes.

We have now identified two abundance archetypes, the multiplicative abundance of information goods and the reproductive abundance of living organisms. Information is a non-material good. Organisms are made of living matter.

Non-living matter is the basis of two more archetypes.

\section{Massive Abundance: A Bulky Gift of Nature}

The two additional archetypes are based on the massive bulk of certain elements and compounds in nature. Air is available to all. Water too, with exceptions. The abundance of sand promises a practically inexhaustible source of silicon, which provides the elemental basis for the hardware infrastructure of the information economy as well as future solar energy economies. The hydrogen in the sun provides the Earth with abundant renewable solar energy that creates its own cascades of abundance. It is solar energy that drives all living systems, the water cycle, the global circulation of air. Properly tapped, it will provide humanity with inexhaustible sources of solar, wind, water and ocean energy that can make dirtier non-renewable sources like fossil and radioactive fuels unnecessary. The third and fourth archetypes are both archetypes of massive abundance of natural elements and compounds found on Earth and elsewhere, another gift of nature, by their sheer bulk, to Homo sapiens.

We use the substances belonging to the massivepersistent abundance archetype for their material content - air, water, sand, minerals, etc., as raw material for the finished products we make. We use the other substances belonging to the massivedissipative archetype for their energy content - coal, oil, natural gas, and so on. 
Because abundance based on persistent mass consists of matter, and matter is never really destroyed, such abundance persists, once it is made available. All the metals dug out of the earth since Homo sapiens started using iron, copper, bronze, tin, aluminum, etc. are still above ground, somewhere - in dumps, basements and cellars, and various nooks and corner of human dwellings, whether in use and abandoned. The persistent type undergo very little chemical transformation during their use. Most of the different metals dug up as ore, processed, and subsequently incorporated into a finished product, possibly ending up as waste, still exist as metal today, slowly oxidizing somewhere. Their persistence allows them to be reused or recycled over and over again, with little additional chemical processing.

The key towards appropriate management of this archetype is a better system of recovering and recycling the resource, to enhance the persistence of these abundant goods for their human users.

Some of the other raw materials are so transformed after use that these are essentially one-time use materials. (Other uses, of course, may be found for the transformed by-products, like using waste heat from cooling condensers for space heating.) These include all those we use for their energy content. We can call them massive-dissipative resources because they are dissipated after use. They are the depletable, exhaustible resources. While we may start with an abundance by virtue of their bulk, the use of the resource transforms and depletes it. Once used, that's it. Given the known reserves and current rates of consumption, for instance, the world's oil reserves are at best good only for a few more human generations. Then they will be gone. Other non-renewable energy resources also fall under this archetype. $^{5}$

The principal management approach for this archetype should be conservation, to leave as much of the resource to future generations, who may discover much better and more efficient ways of putting these non-renewable resources to good use. ${ }^{6}$

5 Some may quibble that solar energy is also depletable because it will run out of hydrogen in a few billion years.

6 For some discussion on possible abundance management approaches, see Verzola 2008, also Verzola (in press).
In addition to the above four, still other archetypes of abundance also exist, such as: ${ }^{7}$

Psychic Abundance. Human needs exist which cannot be met by material, information, or energy goods or services. Beyond the minimum biological requirements of food, water and protection from the elements, for instance, health is as much a matter of happiness, contentment and a sense of community and belonging. It is as much a mental as a physical state. Those who live in voluntary simplicity or even in obvious material lack may still enjoy a sense of abundance that comes from states of emotion and thought that may be variously called psychological, emotional or spiritual.

Derivative Abundance. These types of abundance are derived from the other archetypes. Thus they may take on some of the features of their source, but they may also pose unique features of their own. Wind power, for instance, is a derivative of solar power, with solar heat turning the earth's atmosphere into a heat engine that generates air movements which can then be tapped for energy generation. Part of this heat engine drives the hydrological cycle, from which comes another derivative source of abundance, the power of flowing/falling water. When we learn to build on the foundations of existing abundant resources to create cascades of new abundant phenomena, we will see more new types of derivative abundance.

\section{Pseudo-Abundance: Bads Posing as Goods}

A phenomenon sometimes presents itself as a case of abundance. We may later find out that it comes attached with a darker side of ills and bads. Even worse, the "abundance" may in reality be a poisoned pill of ills and bads that are actually meant to undermine real abundance and create artificial scarcity, but are sold as a good or service that claims to benefit an unsuspecting public. ${ }^{8}$

It may take discernment and time to determine which is which. Who would have thought that farmers will accept - not to mention pay for - powerful poisons into their soils? That mothers would deny their babies the nourishing breast milk nature has

7 For other possible classifications of abundance, see Verzola (in press).

8 For additional discussion, see Verzola (in press). 
freely provided for them, and prefer instead to buy troublesome antibiotic- and hormone-laden formula milk? Have we taken into account the environmental and health costs involved in creating the new ICT infrastructure? Few people today look at the bads associated with ICTs, their production, use, and disposal. The study of abundance must make these costs visible, so that they can be taken into account whenever the cost of digital reproduction is considered, and so that the bads associated with ICTs can also eliminated over time.

We need to be vigilant about these types of "abundance", so we can reject and eliminate them. Unfortunately, our production methods often generate them as a by-product of production. Responding to this negative "abundance" involves avoiding being locked into production methods that rely for raw materials on toxic and non-biodegradable substances or which create them as by-products or as the main product itself, and shifting to technologies of clean production. The model of clean production is the ecological model of food webs, which finds use for every by-product and creates closed production loops.

\section{The Demand Side of Abundance}

Abundance archetypes represent the supply side; let us now look at the demand side. It is almost by definition that economists predominantly focus on scarcity, when they define economics as the study of "the most efficient ways to allocate scarce resources to meet unlimited human wants". If, indeed, people had infinite wants, then not even all the resources of this finite world will be enough for a single person.

It can be argued, however, that consumer wants are not infinite. There exist physical, physiological, psychological and cultural limits - both actual and potential - to consumption which can keep individual as well as collective needs and wants within finite bounds.

If these needs and wants are finite, then satisfying them becomes a real possibility, and relative abundance is within reach.

\section{Finite Wants}

The following concepts will help show that needs and wants can remain within finite bounds:
Satiation. Economists define satiation as the consumption level which the consumer most prefers. The closer the consumer is to this level, writes economist Hal Varian, "the better off he is in terms of his own preferences". ${ }^{9}$ This satiation level for a bundle of goods is also called the bliss point. Beyond it, the consumer prefers to have less of the goods. Many economists still cling to the hedonist principle that "more is always preferred to less." But some acknowledge, at least in theory, that a satiation level exists for some, if not most, goods. Varian, in particular, says that most goods have a satiation point and that "you can have too much of nearly anything," which contradicts the "unlimited wants" assertion in most definitions of economics.

Saturation. While satiation may apply more to the psychological attitude of a consumer not wanting more, saturation is more about the physiological or physical incapacity of a person to consume more. Beyond the saturation point, one's body either will become incapable or will involuntarily reject additional servings of food and drinks. One can only wear so many clothes, or shoes. One can listen to only so many CDs or watch only so many videos. There are only twenty-four hours a day after all.

To reach the brain, a sense stimulus takes around 10-20 milliseconds. To respond in a conscious way, neuro-scientists have found out, the brain takes longer - around 500 milliseconds (half a second). ${ }^{\mathbf{1 0}}$ This suggests that our brain can only enjoy at most two distinct events every second or about 170,000 every twenty-four hours. For a world with some six billion people, that adds up to an upper limit of one quad (i.e., quadrillion) consumption events per day. That is a huge number, it is true, but finite nevertheless. Most of us will probably exceed our saturation levels long before that point.

The argument for saturation is further strengthened by the findings of experimental psychologists that people - and animals too - get less pleasure from any stimulation, the more often it happens. Not only does the pleasure diminish, but the stimulation soon becomes undesirable. ${ }^{11}$ So, the finite time to consciously respond to sensory stimulation sets a limit to the variety of stimulation one can respond to, and a single type of stimulation will also soon become undesirable, likewise setting a limit on the desirable

\footnotetext{
9 Varian p. 43-44.

10 Matthews.

11 Scitovsky p. 35-40.
} 
amount for that type. Economist Tibor Scitovsky has further argued that not all sources of stimulation can be exchanged in the market and therefore add to economic demand. ${ }^{12}$ All these support the argument for a finite bound to consumer needs and wants.

Satisficing. Even before we reach our satiation or saturation levels, we may already reach our "satisficed" level, in which the quantity we have of a particular good or bundle of goods already suffices to satisfy, and beyond which we would only weakly prefer more. ${ }^{13}$ In contrast to satiation, which results in a strictly lower preference beyond the bliss point or satiation level, points beyond the satisficing level are either equally preferred or only so slightly or weakly preferred that it does not make a difference. The idea that consumers satisfice rather than optimize when fitting their wants to their budget was first raised by psychologist Herbert Simon, who subsequently won the Economics Nobel Prize in 1978. ${ }^{14}$

\begin{abstract}
"Inferior" Goods. Still another economic concept supports the idea of limited human wants. This is the concept of "inferior" good, which are goods which we buy less of as our income increases. These tend to be goods which are considered "necessities", and whose consumption tends to plateau and even decrease, as consumers increase their income. The levelling off of consumption is a mark of self-limiting demand.
\end{abstract}

While any of these "sat" concepts - certainly all of them, together - are enough to argue that individual and likewise needs and wants have finite bounds, this paper is inclined to base its definition of abundance on the satisficing concept. On such basis, the following is asserted: some consumers

12 ibid., p. 81-83.

13 Economists often represent the quantity of good desired relative to another good (or other goods) using indifference curves, which include on the same curve equally preferred ratios of one good over another. Through the same graphical tool, "satisficed" levels may then be described using thick indifference curves. Such thick curves mean that small increases in quantity of a consumer's bundle of goods do not increase a consumer's preference for that bundle, suggesting that they have reached their satisficed level. Standard indifference curve analysis can then be used to determine the economic implications when consumers reach this level. One implication, for instance, is that the demand curve turns concave as the satisficing level is approached. This upsets the First Fundamental Theorem of Welfare Economics, which assumes strictly convex indifference curves and non-satiation. This is the theorem which asserts that a free market leads to an optimally efficient allocation of resources.

14 See Simon. have a satisficing level for some goods. ${ }^{15}$ As the price of a good goes down, consumers will then be able to afford enough to reach their satisficing levels. The following stronger assertion is further proposed: all consumers have a satisficing level for some goods. 16

The above assertions lead directly to a formal definition of abundance: when a person can afford enough quantity of a good or bundle of goods to reach his/her satisficed level, then the person enjoys a state of abundance for that good/bundle of goods. The concept is not new. Gandhi must have been referring to abundance when he said "the Earth has enough for everyone's need". This definition also allows a good's state of abundance with respect to one person to be quantified: it is the ratio of that person's affordable quantity (economists call this demand, which varies according to price) to his/her satisficing level, which is the point where any further reduction in price does not anymore increase that person's demanded quantity. For instance, if a person's satisficing level is five pairs of shoes, but s/he can only afford two pairs (i.e., s/he is only willing to buy two pairs at current prices), then $\mathrm{s} / \mathrm{he}$ enjoys a state of abundance of $40 \%$ (two out of five) with respect to shoes. This makes it simple to relate abundance to its inverse, scarcity: the person needs three pairs more to reach the five-pair satisficed level. Thus $s /$ he faces a scarcity level of $60 \%$.

For a group of consumers, the level of abundance can be determined by aggregating the quantities each individual can afford (the demand), divided by the aggregate of their individual satisficing levels. This makes it possible, in theory, to determine the relative level of abundance (and scarcity) of a good for an entire society.

15 "Satisficing" seems to have no noun form. Instead of "satisfaction" - which many economists use to mean "reaching the highest level desired" rather than "meeting a level that suffices" - this paper uses "satisficing level" if the level has not been reached yet, and "satisficed level" if it has been reached.

16 The satisficing principle is widely used in logical/mathematica proofs and, by extension, in all physical, natural and social sciences that use such proofs in their fields. Consider the following assertions: (1) A, B and C imply X; 2) D and E imply X, and 3) $F$ implies $X$. As soon as the truth of (1) is proven, the sufficient conditions for $\mathrm{X}$ will have been satisfied, a very common exercise in many fields. Subsequent work may show that (2) and (3) are also true, with (3) possibly established as the optimal sufficient condition for X. But (1), (2) and (3) are all equally sufficient to satisfy the conditions for $\mathrm{X}$. Anyone who has ever established, used or accepted such proofs is, in effect, using the satisficing principle. 
Economists usually assume that business firms maximize their profits by producing until their marginal cost (the cost of the next additional unit) equals their marginal revenue (unit price of the good). If, in addition to this behavioral assumption, diminishing returns or decreasing returns to scale or equivalently -- increasing marginal costs are also assumed, then the increasing marginal costs will eventually equal the good's market price. In economic theory, this is the point of maximum profit. Thus business firms will, in theory, reach their satiation point when they reach their maximum profits.

This also means, however, that profitable firms employing technologies with constant or increasing returns to scale will face constant or decreasing marginal costs. They will therefore have no profit maximum and likewise no satiation level. These firms will conform to the theoretical hedonist idea that "more is always preferred to less." They will try to keep increasing their scale of operations, in an unending chase for profits - making them an engine of globalization.

It is the profit-motive, it seems, that keeps us away from abundance, not „infinite" human wants.

\section{Aggregate Abundance}

Based on the stronger assertion made above, the level of abundance for a group of consumers can be determined by aggregating the quantities each individual can afford, divided by the aggregate of their individual satisfaction levels. This makes it possible, in theory, to determine the relative level of abundance (and scarcity) of a good for an entire society. ${ }^{17}$

Cooperation among consumers raises the possibility of further improving the aggregate level abundance, given the same supply and individual demands. Sharing resources and cooperative consumption can make it possible for a group of consumers to buy more goods or services and get nearer their satisfaction levels, improving their aggregate level of abundance. A car, for instance, may meet the daily commuting needs of one or multiple persons. Compared to books in someone's shelf, books in a community library can be enjoyed by many more people.

17 Abundance levels that exceed $100 \%$ may be called a state of absolute abundance.
Beyond the pooling of resources, cultural mechanisms can also bring satisfaction levels and demand down, further improving a society's level of abundance. Extolling simple living, highlighting voluntary simplicity, focusing on the spiritual aspects of life, or idealizing asceticism are various ways by which material accumulation is deemphasized and a society's level of abundance enhanced from the demand side. As Gandhi put it when describing his own experiments in voluntary simplicity, "the real seat of taste was not the tongue but the mind." 18

\section{Abundance Studies: A New Field}

Clearly, abundance and its identified archetypes are a common feature of our world. To harness such abundance and build cascades of more abundance for the benefit of human welfare is, as clearly, a desirable goal. Abundance, therefore, deserves our attention as a major field of study and research. If abundance has not gotten the full attention that it deserves, it is for the following reasons:

- Economics has generally focused its attention almost exclusively on scarcity, creating a blind spot among economists.

- It is easy to take for granted an abundant resource like air or soil.

- Powerful economic agents try to either undermine abundance or to subject it to private control, to create artifical scarcity and generate further possibilities for profitmaking.

However, with the emergence of information economies and the growth of information abundance, this phenomenom cannot be denied or ignored anymore. In fact, the economics of abundance is becoming an extremely interesting field of study. This field can draw lessons from the information sciences, life sciences, agriculture, material sciences, physical sciences and of course not only economics but the rest of the social sciences as well.

Elsewhere, I have proposed basic goals for abundance management: 19

\footnotetext{
18 Gandhi p. 52.

19 Verzola (in press).
} 
- Make the source of abundance accessible to more citizens. This is essentially the goal of social justice, for distributing the benefits of abundance to a larger portion of, if not the whole, population.

- Make the source last longer, preferably indefinitely. This is the goal of sustainability. Ideally a source of abundance should be managed so that it will provide the present and future generations with a perpetual stream of benefits.

- Develop an abundance-nurturing ethic that creates among the community of beneficiaries a mindset that is strongly protective of the source of abundance. Aldo Leopold well-known "land ethic ${ }^{\prime \prime 20}$ and Sandra Postel's parallel "water ethic ${ }^{\prime 21}$ are examples of such abundance-nurturing ethic.

- Attain dynamic economic and ecological balance. Unlimited growth is abundance is not possible in a finite world. Abundance in nature can occur indefinitely only when a dynamic balance is attained among abundant elements through closed material cycles. Today, we must learn to cope with four major sources of imbalance: a) our reliance on a non-renewable energy base; b) the linear production processes of industry which deplete our raw material sources and create toxic or nonbiodegradable wates; c) the unchecked growth of human populations; and d) the unlimited corporate drive for profit.

- Build cascades of new abundance. By learning to recognize the conditions that lead to abundance, we may soon learn how to create new abundance patterned after the cascades of abundance found in nature.

20 "A thing is right when it tends to preserve the integrity, stability and beauty of the biotic community. It is wrong when it tends otherwise." See Leopold 1966.

21 "Make the protection of water ecosystems a central goal in all that we do." See Postel 1997

\section{Abundance Creates Commons}

It is clear from these goals that abundance studies feed into another area of current huge interest, the study of the commons. After all, abundance naturally creates the need to manage a common resource. Approaches to commons management have relied on appeals to the common good, and the values of sharing, cooperation, altruism and community spirit, as well as explicit regulatory measures, economic incentive and disincentive systems, cultural norms and practices such as restrictions, prohibitions and taboos, and other institutional mechanisms. Complex social behavior and hierarchies of communal use and access rights have evolved among ancient tribes and other traditional societies, for managing abundance and the commons, and these have served them well for many generations and perhaps for the future as well. Successful modern commons such as free/open source software and the Wikipedia have also evolved their own rules and patterns of behavior for managing the abundance that characterizes the emerging information economy. A rich theoretical and practical heritage in commons management, which has learned to cope with and to manage both abundance and scarcity, may be found in the literature of the commons. ${ }^{22}$ These should serve us well in subsequent abundance studies.

\section{Conclusion}

The new technologies in information and communications have created a new type of good whose outstanding feature is its abundance. The abundance of information goods has made them cheaper relative to other goods, leading to a massive process of substitution, as consumers and producers shift to information goods away from physical goods. Aside from the abundance inherent in information goods, which this paper calls multiplicative abundance, biological abundance may also be found in nature, given the inherent urge and ability of all living things to reproduce their own kind, thus the term reproductive abundance. A third type of abundance is the massive abundance of such materials as sand, water and air. The creation of other abundance out of these archetypes can lead to a cascade of derivative abundance, which if properly tapped promises a life of plenty for human societies. However, one

22 Ostrom, Dietz, et al. 
must also beware of pseudo-abundance, which consists of bads and ills posing as goods.

The promise of abundance can turn into reality not only due to huge increases in the supply of goods, but also when the demand for goods itself is limited, as can happen when satiation, saturation or satisficing occurs. With finite wants, the attainment of true abundance becomes a real possibility. The literature of the commons provides a rich source of material for studying the management of abundance.

These considerations justify the emergence of a new field of abundance studies, that will look at the economics of production and consumption of goods not only from the perspective of scarcity but also of abundance. After all, a major goal of any economy and by extension any economist - should be to realize abundance for all.

\section{Works Cited}

Anderson, Chris. The Long Tail: How Endless Choice is Creating Unlimited Demand. London: Random House Business Books, 2006.

Gandhi, M. K. An Autobiography (The Story of My Experiments with Truth). Ahmedabad: Navajivan Publishing House, 1927.

Gershenfeld, Neil. When Things Start to Think. New York: Henry Holt \& Co., 1999.

Hunt, Jessica. "Nanosolar's Breakthrough - Solar Now Cheaper than Coal". (Nov. 23 2007). $<$ http://www.celsias.com/article/nanosolarsbreakthrough-technology-solar-now-cheap $>$.

Leopold, Aldo. A Sand Country Almanac. Ballantine Books: New York, 1966.

Matthews, Robert. 25 Big Ideas: The Science That's Changing Our World. Oxford: Oneworld Publications, 2007.

Ostrom, Elinor, Dietz, Thomas, et. al. (Eds.). The Drama of the Commons. Washington, D. C.: National Academy Press, 2002.

Postel, Sandra. Last Oasis: Facing Water Scarcity. W.W.Norton, New York, 1997.

Rich, Emma. "Nanosolar grabs $\$ 300$ million for utility solar". (Aug. 27 2008). $<$ http://cleantech.com/news/3311/nansolargrabs-300-million-utility-solar-thin-film>.

Samuelson, Paul, and Nordhaus, William. Economics. $14^{\text {th }}$ ed. New York: McGraw-Hill, 1992.
Scitovsky, Tibor. The Joyless Economy: An Inquiry Into Human Satisfaction and Consumer Dissatisfaction. London: Oxford University Press, 1976.

Simon, Herbert. „A Behavioral Model of Rational Choice." The Quarterly Journal of Economics Vol. 69 No. 1 (Feb 1955). 99-118.

Varian, Hal. Intermediate Economics: A Modern Approach. $4^{\text {th }}$ ed. New York: W. W. Norton \& Co, 1996.

Verzola, Roberto. "Studying Abundance”. 2008. $<$ http://rverzola.wordpress.com/2008/11/studyi ng-abundance-1.pdf $>$.

Verzola, Roberto. „Undermining Abundance." In Gaelle Kirkorian and Amy Kapcinsky (Eds.). From Intellectual Property Rights to Global Knowledge Sharing. New York: Zone Books. (in press).

<http://rverzola.wordpress.com/2008/11/verzol a-on-abundance1.pdf0 > . 